\title{
Estudo retrospectivo dos acidentes traumáticos da máo relacionados ao trabalho ${ }^{1}$
}

\author{
Tamara Pereira de Oliveiraa ${ }^{a}$ Mariana Midori Sime ${ }^{b}$, \\ Jucimara Firmo Barreto Costa ${ }^{c}$, Iracema Serrat Vergotti Ferrigno ${ }^{d}$
}

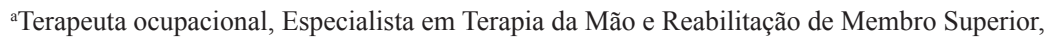
Universidade Federal de São Carlos - UFSCar, São Carlos, SP, Brasil

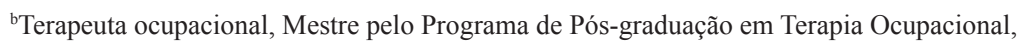
Universidade Federal de São Carlos - UFSCar, São Carlos, SP, Brasil. Professora Assistente do Curso de Terapia Ocupacional da Universidade Federal do Espírito Santos, UFES, Vitória, ES, Brasil

'Terapeuta ocupacional, Doutora em Ciências da Saúde, Faculdade de Ciências Médicas da Santa Casa de São Paulo - FCMSCSP, Mestre em Ciência da Saúde/Reabilitação, Universidade Federal de São Paulo - UNIFESP, Especialista em Terapia da Mão e Reabilitação de Membro Superior, Instituto de Ortopedia e Traumatologia do Hospital das Clínicas da Faculdade de Medicina da Universidade de São Paulo - IOT-HCFMUSP, São Paulo, Pró-Reumato - Clínica Integrada para Pacientes Reumáticos, Jundiaí, SP, Brasil

${ }^{d}$ Terapeuta ocupacional, Doutora pelo Programa de Cirurgia Experimental, Faculdade de Ciências Médicas da Universidade Estadual de Campinas - FCM-UNICAMP, Campinas, Docente do Departamento de Terapia

Ocupacional e do Programa de Pós-graduação em Terapia Ocupacional, Universidade Federal de São Carlos - UFSCar, São Carlos, SP, Brasil
\end{abstract}

\begin{abstract}
Resumo: A mão é um instrumento intensamente usado nas atividades de vida diária, atividades de vida prática e profissional, sendo assim, frequentemente lesionada, causando impacto na produtividade e na economia do país, além de afetar a qualidade de vida do indivíduo. Quando a lesão está relacionada ao trabalho deve haver notificação e encaminhamento, por parte da unidade de atendimento, ao Centro de Referência de Saúde do Trabalhador (Cerest). No entanto, ainda são pouco explorados os sistemas de registros dos acidentes de trabalho no Brasil. Assim, o objetivo deste trabalho foi realizar um levantamento retrospectivo de dados sobre lesões traumáticas das mãos de pacientes atendidos no Cerest de Jundiaí-SP, visando conhecer o perfil dos acidentados. Os dados foram colhidos dos registros da ficha SINAN - Ficha de Investigação Acidente de Trabalho Grave, no ano de 2009. Dos 416 casos registrados na SINAN, 45,2\% são de acidentes na mão, notificados em sua maioria por hospitais particulares. O acidente ocorreu em 70,7\% na cidade de Jundiaí, sendo 88,3\% dentro da empresa. Os homens, na faixa etária de 19 a 39 anos, foram os mais acometidos. A função exercida relacionada à maior incidência de acidentes foi operador de máquina, e a fratura foi o diagnóstico mais frequente. A incapacidade temporária atingiu $80,3 \%$ dos trabalhadores. $89,3 \%$ possuem carteira assinada. Aponta-se a necessidade de investimento nos sistemas de registro de acidentes de trabalho para evitar a subnotificação, aumentar a conscientização do trabalhador e de órgãos públicos quanto à prevenção e à reabilitação, evitando a incapacidade do trabalhador e prejuízo para empresa e governo.
\end{abstract}

Palavras-chave: Acidentes de Trabalho, Traumatismos da Mão, Prevenção de Acidentes, Notificação de Acidentes de Trabalho.

Autor para correspondência: Jucimara Firmo Barreto Costa, Núcleo de Assistência a Pessoa com Deficiência, Prefeitura de Jundiaí, Rua Barão de Teffé, 458, CEP 13208-760, Jundiaí, SP, Brasil, e-mail: jucimarafbarreto@ hotmail.com

Recebido em 22/3/2012; Revisão em 9/8/2012; Aceito em 17/10/2012. 


\title{
Retrospective study of work related traumatic hand injuries
}

\begin{abstract}
The hand is an instrument extensively used in daily life activities - practical and professional; and it is, consequently, often injured, causing impact on productivity and on the country's economy, also affecting the quality of life of individuals. When the lesion is work-related, it should be reported and referred by the service unit to Worker Health Reference Centre (CEREST). However, systems of records of occupational accidents are still little explored in Brazil. The aim of this work was to conduct a retrospective data survey on hand traumatic injuries of patients treated at CEREST in the municipality of Jundiaí, Sao Paulo state, in order to know the profile of these victims. Data were collected from the records of SINAN card - Severe Accident Research Sheet, in 2009. Of the 416 cases reported at SINAN, $45.2 \%$ were accidents involving the hand, which were reported mostly by private hospitals. $70.7 \%$ of the accidents reported occurred in the city (Jundiai) and $88.3 \%$ of them took place within the premises of companies. Men aged between 19 and 39 years old were the most affected. Machine operators presented the highest accident incidence and fracture was the most frequent diagnosis. Temporary disability reached $80.3 \%$ of workers. $89.3 \%$ worked under formal contracts. Investment in record systems of labor accidents is essential because it would prevent underreporting and improve awareness of employees and public agencies regarding prevention and rehabilitation, thus avoiding inability of workers and damage to businesses and the government.
\end{abstract}

Keywords: Occupational Accidents, Hand Injuries, Accident Prevention, Occupational Accident Registry.

\section{Introdução}

Com as mãos, o ser humano pode realizar uma infinidade de variações de preensōes-ações e adaptar-se aos mais diversos usos, diferenciar tipos de espessuras, pesos, distâncias e temperaturas. Por isso ela é chamada de "educador da vida" e é a parte do corpo que mais transmite nossa individualidade (FERRIGNO, 2007; LEITE, 2006).

Considerando que é a mão o membro mais usado durante a maioria das atividades da vida diária, é ela que empurra, puxa, segura, solta, manipula, cozinha, costura e ainda ajuda na locomoção, o risco de ser lesionada é maior e, quando os membros superiores apresentam algum déficit, as atividades profissionais, atividade de vida diária (AVD) e atividade de vida prática (AVP) serão realizadas com maior limitação. Isso pode ocasionar mudanças de papéis familiares, incapacidades, baixa autoestima, perdas sociais, entre outros (FERRIGNO, 2007; LEITE, 2006).

Acidentes que acometem as mãos já são considerados epidemia, principalmente acidentes de trabalho e os decorrentes da violência urbana, atingindo diretamente a situação econômica e a qualidade de vida do indivíduo, ocasionando com frequência o afastamento do trabalho e prejuízo ou até mesmo incapacidade nas AVDs e AVPs. As lesôes relacionadas ao trabalho são inúmeras, provenientes de traumas como queimaduras, eritemas, fraturas, esmagamentos e amputaçôes (FIGUEIREDO et al., 2006; MATTAR JUNIOR, 2001).
O surgimento de novas tecnologias fez com que o número de cargos de trabalho aumentasse e intensificou o ritmo da jornada, gerando uma transformação nas relaçôes trabalho-emprego. A taxa de desemprego diminuiu à custa do aumento dos trabalhos informais, sendo que estes estão relacionados com atividades mais perigosas do que as relacionadas aos trabalhos formais (DIAS; HOEFEL, 2005). Pardini e os cirurgiôes de mão de Belo Horizonte, em 1990, em sua análise de 1.000 acidentes em membros superiores, demonstram que os equipamentos mecânicos são os principais agentes causadores de lesôes, atingindo indivíduos do sexo masculino entre 20 e 45 anos de idade, com impactos econômicos e sociais (PARDINI JUNIOR et al., 1990). Um grande problema apresentado atualmente é que a maioria dos trabalhadores informais não registra o acidente de trabalho, dificultando assim o controle e possível resolução dos casos de acidentes (SILVA; GUIMARÃES; RODRIGUES, 2007). Dos acidentes de trabalho registrados no Brasil, Silva, Guimarães e Rodrigues (2007) informam que, em 2003, 41,1\% atingiram o membro superior e, desses, 34,2\% são acidentes que acometeram até o nível do punho.

Diversos estudos enfatizam a correlação entre faixa etária, sexo, causas mais comuns e tipos de lesōes em acidentados de mão. Tem-se observado maior incidência de acidentes em jovens do sexo masculino, nos quais são mais frequentes as lesōes de tendão, 
seguidas de fraturas e lesóes nervosas. Os profissionais mais atingidos são os marceneiros e trabalhadores de indústrias, visto que somente uma minoria faz uso dos equipamentos de proteção (BATISTA; FILGUEIRA, 1997; FIGUEIREDO et al., 2006; LEBRÃO; JORGE; LAURENTI, 1997).

Os acidentes de trabalho causam um grande impacto sobre a produtividade e a economia do país. Estima-se que $4 \%$ do produto interno bruto (PIB) sejam direcionados para saúde do trabalhador, e quanto ao sistema de seguridade, as incapacidades permanentes representaram cerca de $5 \%$ a $10 \%$ do total de benefícios (DIAS; HOEFEL, 2005).

$O$ processo de reabilitação tem um papel primordial no retorno do trabalhador acidentado às suas funçóes/papéis e, paralelamente, na redução dos custos e perdas para o empregador causado pelo afastamento. $\mathrm{O}$ tratamento conservador frequentemente tem bons resultados, mas certos casos necessitam de cirurgia. Esse tipo de procedimento é preocupante tanto para os médicos, pois o tratamento é mais invasivo e o processo de recuperação é mais delicado, quanto para o governo, pois o custo do tratamento cirúrgico é mais elevado do que o conservador (SILVA; GUIMARÁES; RODRIGUES, 2007).

Para diminuir os acidentes é importante aumentar e melhorar a fiscalização no local de trabalho, visando indicar meios de prevenção de acidentes (BORSOI, 2005). Lacaz (2007, v. 23, p. 763, grifo do autor) reforça trechos de algumas resoluçóes da $3^{a}$ Conferência Nacional de Saúde do Trabalhador, realizada em novembro de 2005, sobre essa situação:

Eleger como prioridade de fiscalização, pelos Ministérios do Trabalho [...], da Saúde e do Meio Ambiente, o trabalho e as condiçóes do desenvolvimento do trabalho...

$\mathrm{O}$ autor ainda enfatiza que as resoluçôes foram orientadas por uma visáo que se dirige aos órgáos de fomento:

Priorizar a destinação de recursos das instituiçôes de pesquisa para apoiar estudos das condiçôes de trabalho, identificando os fatores determinantes e condicionantes dos agravos à saúde, visando a eliminar os riscos de acidentes [...] e doenças relacionadas ao trabalho, em decisão conjunta dos Ministérios da Saúde, da Previdência [...] e do Trabalho... (LACAZ, 2007, v. 23, p. 763, grifo do autor).

O Ministério do Trabalho (MT) criou um Plano de Trabalho em Saúde do Trabalhador no Sistema Único de Saúde (SUS) para potencializar o serviço destinado ao trabalhador, o Centro de Referência em Saúde do Trabalhador (Cerest). O financiamento das ações na Saúde do Trabalhador aumentou, conseguindo formar 111 Cerests até 2005, em vista que em 2002 havia apenas 11 (DIAS; HOEFEL, 2005).

Entretanto, ainda são escassos os indicadores das condiçóes de trabalho e saúde no Brasil, e insuficientemente explorados os sistemas de registros dos acidentes de trabalho (CORREA; ASSUNÇÃO, 2003; SANTANA et al., 2006).

Dessa maneira, o objetivo deste trabalho é realizar um levantamento retrospectivo de dados sobre lesôes traumáticas das mãos por meio de amostra populacional de pacientes atendidos no Cerest da cidade de Jundiaí-SP, visando conhecer o perfil dos acidentados de mão.

No Cerest o atendimento é referenciado, ou seja, é preciso passar pelas unidades de saúde primárias ou secundárias para receber o encaminhamento de referência, assim o Cerest retorna a contrarreferência. Quando, logo após o acidente de trabalho, o trabalhador é atendido no setor terciário, é preenchida uma ficha para notificar ao Cerest. São 5 os hospitais de Jundiaí que possuem essa ficha: 4 particulares (Hospital Paulo Sacramento, Hospital Santa Elisa, Hospital Sobam e Unimed) e um público (Hospital de Caridade São Vicente de Paulo).

O Cerest de Jundiaí abrange as seguintes cidades do estado de São Paulo: Atibaia, Bom Jesus dos Perdóes, Campo Limpo Paulista, Itatiba, Jarinu, Jundiaí, Louveira, Morungaba, Nazaré Paulista, Várzea Paulista e Vinhedo. A economia dessas cidades é baseada nos setores de serviços e industrial. $\mathrm{Na}$ cidade de Jundiaí o setor de serviços chega a 41\%, e o industrial a $29 \%$ da economia.

A equipe de trabalho do Cerest de Jundiaí é composta de três médicos, uma enfermeira, um engenheiro de segurança, um técnico de enfermagem, uma fonoaudióloga, um motorista e três auxiliares administrativos.

\section{Método}

Estudo do tipo retrospectivo descritivo sobre acidentes de mão, notificados no Cerest da cidade de Jundiaí-SP durante o ano de 2009.

O Cerest de Jundiaí utiliza dois tipos de fichas para notificar o acidente de trabalho: a RAAT (Registro de Atendimento de Acidente de Trabalho), elaborada pelo Cerest e a SINAN (Sistema de Informação de Agravos de Notificação), elaborada pelo MS, sendo que a primeira é para notificar acidentes leves e a 
segunda para notificar acidentes de moderados a graves, segundo o protocolo do MS - CID-10.

Neste estudo os dados foram colhidos mediante o registro da ficha SINAN - Ficha de Investigação Acidente de Trabalho Grave. As fichas SINAN são anexadas em arquivos separados por mês.

Para a pesquisa foram coletadas da ficha SINAN as seguintes informaçôes: 1) Município de ocorrência do acidente; 2) Unidade de saúde notificadora; 3) Idade; 4) Sexo; 5) Etnia; 6) Escolaridade; 7) Município de residência; 8) Ocupação/função; 9) Situação no mercado de trabalho; 10) Local onde ocorreu o acidente; 11) O empregador é empresa terciária; 12) Código da causa do acidente CID-10; 13) Diagnóstico da lesão CID-10; 14) Evolução do caso; 15) Emissão ou não da Comunicação de Acidente no Trabalho - CAT; 16) Partes do corpo atingidas. As outras questôes da ficha não eram relevantes para a pesquisa (MINISTÉRIO..., 2008).

Foram excluídas fichas RAAT que estavam anexadas ao arquivo das fichas SINAN. Como é a equipe administrativa do pronto-socorro quem preenche a ficha, é frequente o preenchimento da ficha RAAT em caso de acidente grave e, quando chega ao Cerest, esta ficha é anexada junto à SINAN, por ser classificado como acidente grave. Estando o acidente grave preenchido na RAAT as informaçóes são mais simplificadas, o que interferiria na análise dos resultados.

Foram adotadas as denominaçôes dos traumatismos das mãos classificados segundo a Classificação Internacional de Doenças (CID-10) proposta pelo Ministério as Saúde (2008).

\section{Resultados}

De janeiro a dezembro de 2009, foram notificados 1.047 acidentes considerados graves, segundo o Ministério da Saúde, mas somente 416 casos foram preenchidos na ficha SINAN, o restante foi preenchido em ficha RAAT. Assim, 40\% dos acidentes graves neste período faráo parte da amostra da pesquisa. Dessas fichas foram analisadas somente as registradas com acidentes de mão, totalizando 188 (45,2\% das fichas selecionadas) (Figura 1).

Jundiaí foi a cidade de maior ocorrência de acidentes, com 133 casos (70,7\%). Esse dado se justifica por ser o município com maiores oportunidades de emprego e ser o maior polo industrial da região. A segunda cidade com maior ocorrência de acidentes foi Cajamar, com 14 notificaçôes, e o restante foi bem distribuído nas cidades da região. Nota-se que outras cidades que não estáo incluídas na abrangência do Cerest de Jundiaí correspondem maior notificação que outras que estão incluídas, como: Cajamar, Cabreúva, Caieiras, Francisco Morato e Itupeva (Figura 2).

As unidades de saúde notificadoras, ou seja, os hospitais que prestaram atendimento ao trabalhador, de maior ocorrência, foram os hospitais particulares de Jundiaí com 88,8\% ( $\mathrm{n}=167)$, que oferece atendimento particular e por convênio. $\mathrm{O}$ hospital público de Jundiaí notificou $11,2 \%(\mathrm{n}=21)$ dos acidentes graves.

A faixa-etária de maior ocorrência variou entre 19 e 39 anos, para melhor visualização a faixa etária foi dividida da seguinte maneira: menor de 18 anos $(11,7 \% ; \mathrm{n}=22)$, de 19 a 29 anos $(29,8 \%$; $=56)$, de 30 a 39 anos (29,2\%; $\mathrm{n}=55)$, de 40 a 49 anos $(17,5 \% ; \mathrm{n}=33)$, de 50 a 59 anos $(9 \% ; \mathrm{n}=17)$ e maior de 60 anos $(2,6 \% ; n=5)$.

Nota-se maior ocorrência na faixa etária jovem de idade produtiva (Figura 3).

O sexo masculino correspondeu a $92 \%(\mathrm{n}=173)$ dos casos de acidente de mão, e apenas $8 \%(\mathrm{n}=15)$ correspondem ao sexo feminino. O número de casos em mulheres não alcançava três ao mês, chegando a zero na maioria dos meses.

O município de residência do trabalhador acidentado variou entre 24 cidades. O número de acidentes na cidade de Jundiaí não corresponde ao número de residentes nesta, o que revela que muitas pessoas se deslocam de sua cidade para trabalhar e que também pode haver prestadoras de serviço às empresas de Jundiaí (Figura 4).

Os cargos que levam a ocorrência de acidentes de mão com maior frequência foram os que atuam em máquinas e metalúrgicos, $40 \%$ e $13,3 \%$ respectivamente, e a maioria das funçóes utiliza instrumentos de trabalho que proporcionam risco de acidente como pedreiro, marceneiro, padeiro, entre outros (Figura 5).

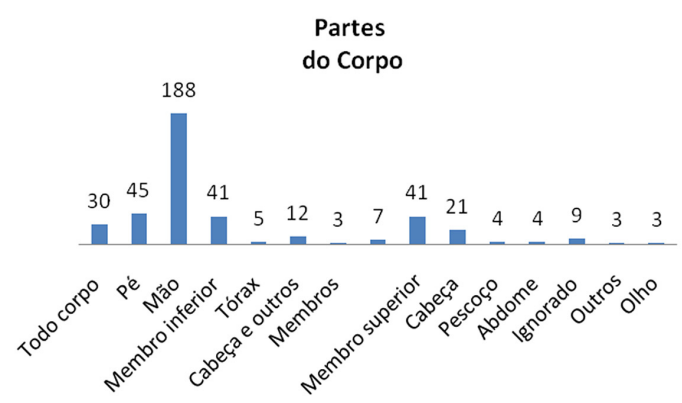

Figura 1. Partes do corpo atingidas no acidente no total das fichas SINAN do ano de 2009. 


\section{Município da ocorrência do Acidente}

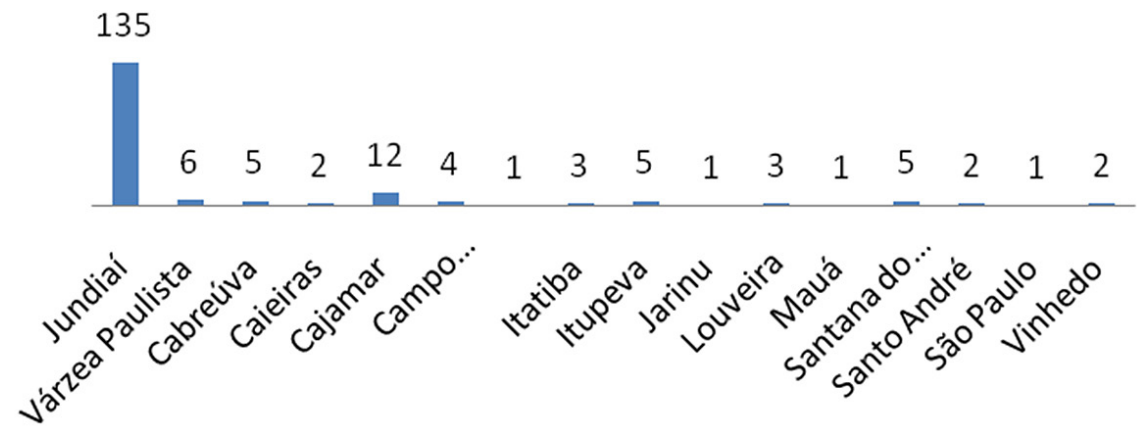

Figura 2. Município de ocorrência do acidente, da amostra estudada.

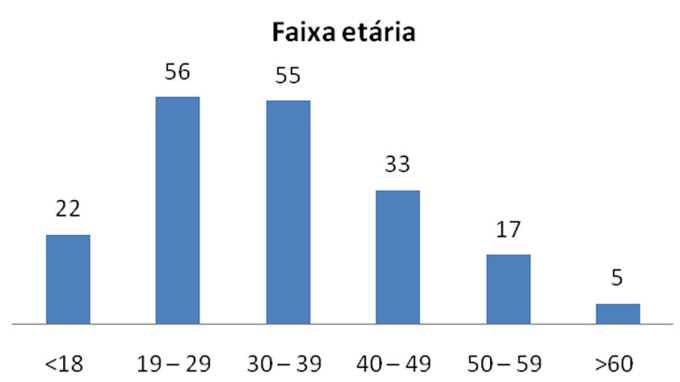

Figura 3. Faixa etária dos acidentados de mão da amostra estudada.

A maioria dos trabalhadores acidentados de mão registrados na ficha SINAN possui registro em carteira de trabalho $(89,3 \%)$ e apenas $2,1 \%$ não havia registro. $\mathrm{O}$ restante foi distribuído entre aposentados, autônomos, servidores públicos estatutário, e 5,3\% das fichas não tiveram esse dado respondido (Figura 6).

$\mathrm{O}$ acidente de trabalho ocorreu dentro da empresa em $88,3 \%$ dos casos e apenas $6,9 \%$ em via pública. Menos de $1 \%$ dos acidentes ocorreu em domicílio próprio e instalações de terceiros, o que possibilita a intervenção na própria empresa (Figura 7).

Os trabalhadores não eram de empresas terceirizadas em $87,7 \%(\mathrm{n}=165)$ dos casos. Apenas $2,1 \%(n=4)$ eram terceirizados e $2,6 \%(n=5)$ não se aplica, o restante foi ignorado $(n=14)$.

As causas dos acidentes foram variadas, mas em $30,8 \%$ a causa, de acordo com o CID-10 (BRASIL, 2008), foi W31 - contato com máquina, em 26,5\%; W23 - esmagamento. O restante foi dividido entre 28 causas (Figura 8).

O diagnóstico da lesão mais frequente foi, de acordo com o CID-10 (BRASIL, 2008),
S62.6 - fratura de dedos, com 37,7\%. O restante foi distribuído entre 24 diagnósticos de lesão (Figura 9).

Com relação aos acidentes, $80,3 \%$ acarretaram em incapacidade temporária, $6,9 \%$ evoluíram para cura e $8 \%$ levaram à incapacidade parcial, ou seja, o tempo de recuperaçáo foi maior ou o tipo da lesão foi mais grave (Figura 10).

As questóes etnia, escolaridade e emissão de comunicação de acidente no trabalho - CAT não foram possíveis fazer análise, pois essas informações não foram coletadas no momento do preenchimento da ficha. Algumas questóes não são obrigatórias para o lançamento da ficha SINAN no programa informatizado do MS. Etnia, escolaridade e emissão de comunicação de acidente no trabalho fazem parte dessas questôes, por isso muitas vezes não são preenchidas. Assim, não houve como relacioná-las.

\section{Discussão}

Foram notificados no Cerest em 20091.047 casos de acidentes de trabalho. Desses foram selecionadas 416 fichas (40\%), o que torna a amostra relativamente pequena para uma discussão fidedigna. No entanto, este estudo fornece informaçóes que correspondem com a literatura a respeito do tema.

Verificou-se que o Cerest de Jundiaí atende outras cidades que não estão incluídas na sua abrangência, assim o número real de acidentes de trabalho da região de Jundiaí fica distorcido. A cidade de Cajamar teve 14 casos de notificação de acidente e, mesmo que seja uma cidade de abrangência do Cerest de Franco da Rocha, ela se localiza na fronteira de Jundiaí, o que pode justificar a notificação ter sido feita no Cerest de Jundiaí. Outro fator pode ser a qualidade de atendimento em saúde e recursos que essa cidade oferece e, principalmente, pelo dever de 


\section{Município de Residência}

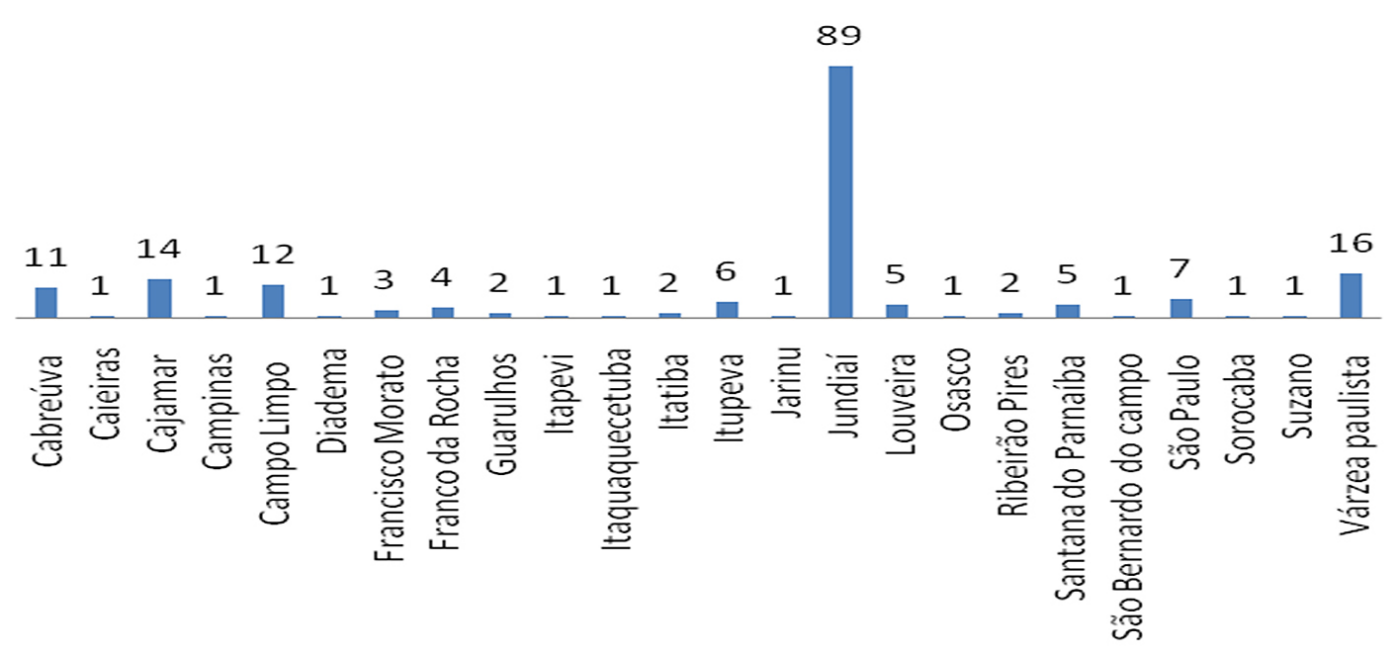

Figura 4. Município de residência do trabalhador da amostra estudada.

\section{Ocupação}

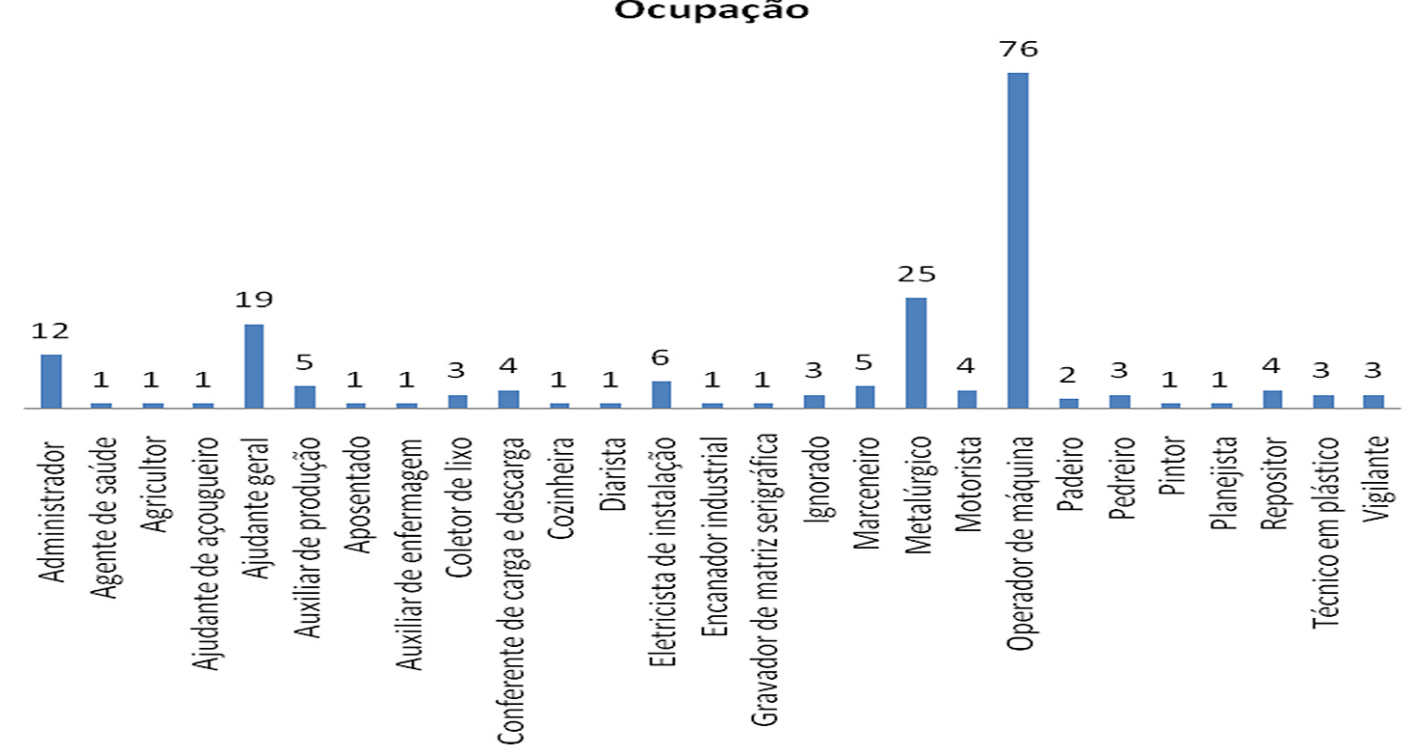

Figura 5. Ocupação/função dos trabalhadores acidentados da amostra estudada.

Situação no Mercado de Trabalho

Aposentado Autônomo Ignorado $\begin{gathered}\text { Não } \\ \text { registrado }\end{gathered}$

Figura 6. Situação no mercado de trabalho do acidentado de mão da amostra estudada referente ao ano de 2009. 


\section{Local do Acidente de Trabalho}

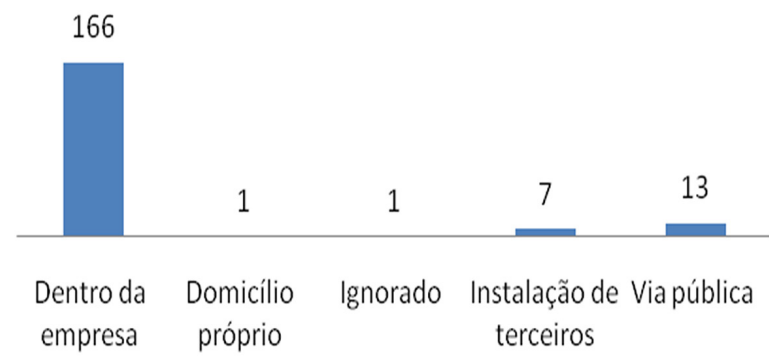

Figura 7. Local do acidente de trabalho da amostra estudada.

\section{Incidência de Acidentes por Código da Causa (CID-10)}

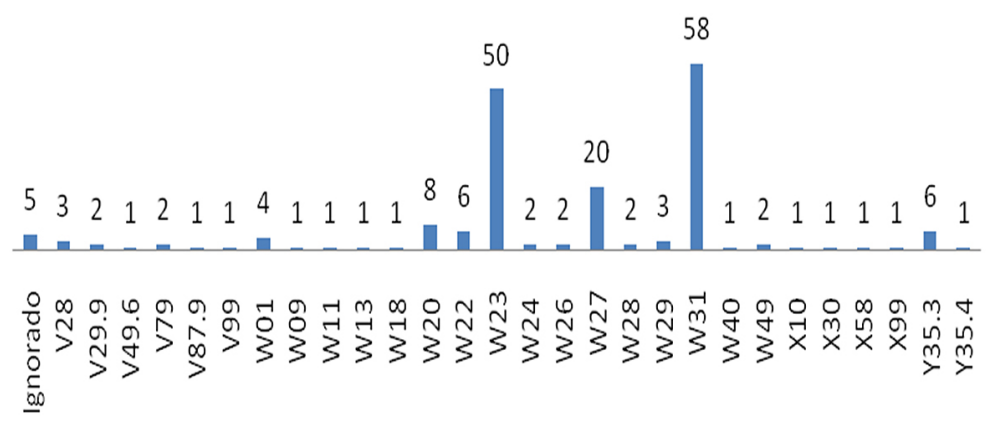

Figura 8. Causa do acidente de acordo com o CID-10 (BRASIL, 2008). Anexo 1

\section{Diagnóstico da Lesão (CID-10)}

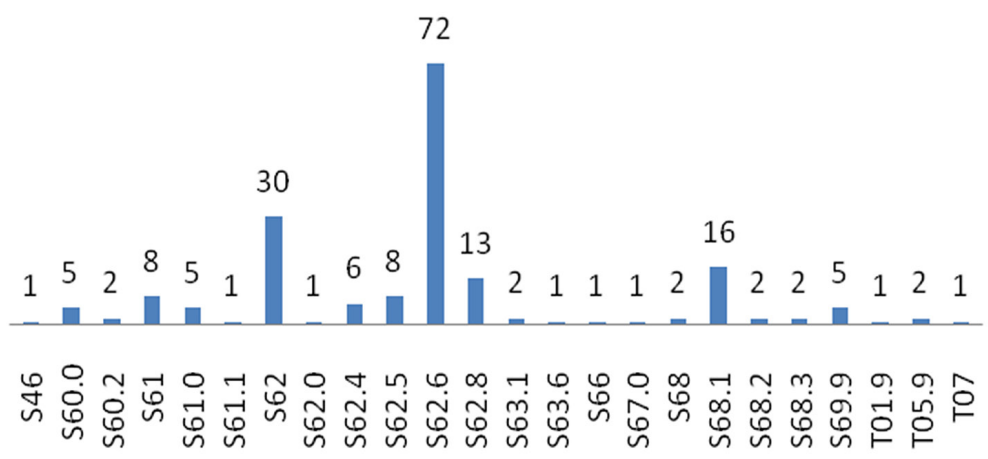

Figura 9. Diagnóstico da lesão de acordo com o CID-10 (BRASIL, 2008). Anexo 2

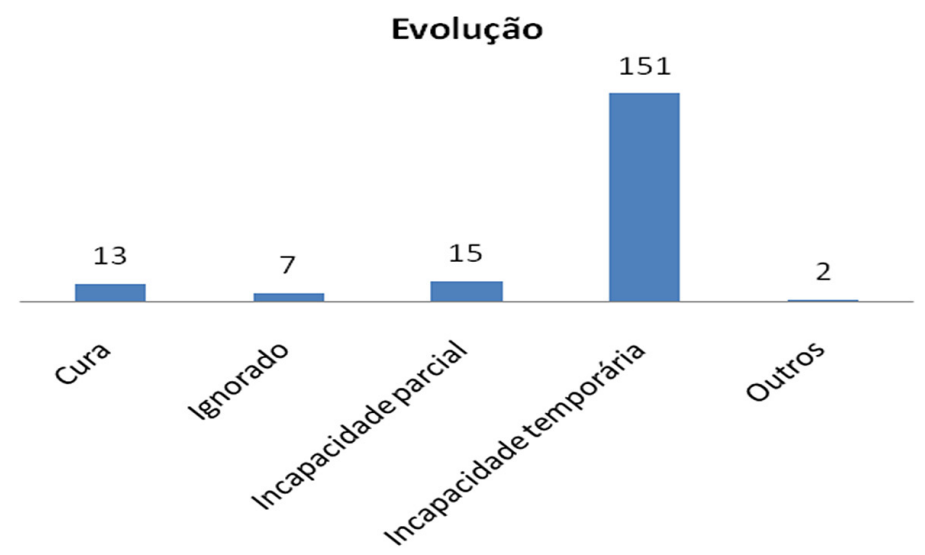

Figura 10. Evolução da lesão da amostra estudada referente ao ano de 2009. 
atendimento em saúde que não pode ser negado em qualquer circunstância.

Comparando as unidades de saúde notificadoras em Jundiaí, verifica-se que o hospital público de Jundiaí atendeu apenas $11,2 \%$ da amostra em estudo, e quase $90 \%$ dos atendimentos ocorreram em hospitais particulares, contrariando a informação de que a grande maioria da população é usuária do sistema público de saúde. Acredita-se que haja subnotificação ao Cerest de todos os hospitais, mas principalmente do hospital público.

Segundo Figueiredo et al. (2006) e Batista e Figueira (1997) os homens sofrem mais lesôes nas mãos, pois frequentemente assumem funçóes que lidam com máquinas e estas favorecem o acidente nas mãos. Os homens são predominantes nesse setor, na faixa etária jovem-adulto, como revelam os dados da pesquisa e a literatura.

Os cargos de trabalho que mais ocasionaram lesões na mão foram os de operador de máquinas e metalúrgico. Jundiaí é uma cidade com o setor industrial em destaque, o que justifica a máquina ser o principal agente causador de acidente de trabalho, apresentando um número alto de acidentes $(57,4 \%)$, considerando esmagamento e contato com máquina.

Com relação ao registro em carteira de trabalho, verificou-se que $89,3 \%$ dos trabalhadores são registrados, o que pode ser explicado por a maioria da amostra ter tido como unidade de saúde notificadora uma empresa contratada. Quando a unidade notificadora é pública, o número de trabalhadores não registrados poderia ser diferente, pois a maioria destes não registra o acidente, como relatam Silva, Guimarães e Rodrigues (2007).

De acordo com a Figura 9, a maioria dos acidentes ocorreu dentro da empresa, o que pode facilitar o trabalho de prevenção destes, pois o causador está na própria empresa. Por outro lado, os casos de acidentes fora da empresa, em via pública ou em domicílio próprio podem não ter sido registrados como acidentes de trabalho.

A maioria da amostra náo trabalha para empresa terciária, o que pode favorecer o incentivo à recuperação do acidentado. Com o retorno à função mais rápido, a empresa não precisará fazer remanejo de função para substituir o trabalhador que se encontra afastado para recuperação.

A lesão mais frequente em decorrência do esmagamento e contato com máquina foi fratura de dedo, seguida de fratura de punho. Em aproximadamente $12 \%$ da amostra ocorreu amputação, sendo desfavorável tanto para o empregado quanto para o empregador. Nesses casos o período de afastamento aumenta, pois o período da reabilitação é maior, devido às alterações da função da mão levando a incapacidades que provocam mudança de vida para o trabalhador.

$\mathrm{Na}$ grande maioria da amostra o tipo da lesão causou incapacidade temporária, levando a tempo indeterminado de afastamento do trabalho, necessidade de reabilitação para promover a cura, se possível, ou até mesmo adaptação para outra função.

A emissão de comunicaçáo de acidente de trabalho (CAT) não foi informada na ficha SINAN, assim não há possibilidade de fazer uma análise real. Dados da Previdência Social indicam que, em Jundiaí, o total de notificaçôes na CAT em 2007 foi 2.851 e em 2008 foi 3.460. O total de notificaçóes sem CAT registrado em 2007 foi 746 e em 2008 foi 772. O INSS também informa o número de óbitos: em 2007 foram 14, e em 2008, 9 (BRASIL, 2008). Santana et al. (2006) e Machado e Gomez (1994) já relataram que os sistemas de registro de acidentes de trabalho hoje existentes fornecem uma informação não suficientemente explorada.

\section{Conclusão}

Os resultados da pesquisa seriam mais fidedignos se o número da amostragem fosse maior, mas de acordo com os dados colhidos da amostra em questão concluímos que $45,2 \%$ dos acidentes de trabalho do ano de 2009, notificados ao Cerest de Jundiaí, afetam a mão. O perfil desse trabalhador é em sua maioria do sexo masculino, com idade entre 19 e 39 anos, trabalhadores de indústria. As principais causas de acidentes foram contato com máquina e esmagamento entre objetos ocasionando, principalmente, fraturas de punho e dedos, e uma pequena percentagem de amputaçóes de dedo. A evolução do trauma levou à incapacidade temporária, o que justificaria um intenso trabalho de intervenção primária e secundária, ou seja, prevenção do acidente e reabilitaçáo da lesão para impedir a incapacidade do trabalhador e prejuízo para empresa. Consequentemente haveria diminuição do envolvimento do serviço terciário, reduzindo a superlotação dos leitos em hospitais. Observa-se a importância do trabalho do Cerest na conscientização do trabalhador formal e informal, de empresas e de hospitais para que não haja subnotificação de acidentes relacionados ao trabalho, tanto em ficha SINAN quanto na CAT. Aponta-se ainda a necessidade de concretizaçáo de projetos de prevenção e reabilitação em saúde do trabalhador. 


\section{Referências}

BATISTA, K. T.; FILGUEIRA, I. C. Trauma complexo de mão: análise epidemiológica na Unidade de Cirurgia Plástica do Hospital Regional da Asa Norte/FHDF. Revista de Saúde do Distrito Federal, Brasília, v. 8, n. 4, p. 25-31, 1997.

BORSOI, I. C. F. Acidente de trabalho, morte e fatalismo. Psicologia \& Sociedade, Porto Alegre, v. 17 , n. 1, p. 17-28, 2005. http://dx.doi.org/10.1590/ S0102-71822005000100004

BRASIL. Ministério da Previdência Social - MPAS. Anuário Estatístico de Acidentes do Trabalho 2008. Brasília: MPAS, 2008. Disponível em: <http://www.mpas.gov.br/ conteudoDinamico.php?id=901>. Acesso em 10 out. 2011.

CORREA, P. R. L.; ASSUNÇÃO, A. A. A subnotificação de mortes por acidente de trabalho: estudos de três bancos de dados. Epidemiologia e Serviços de Saúde, Brasília, v. 12, n. 4, p. 203-212, 2003.

DIAS, E. C.; HOEFEL, M. G. O desafio de implementar as açóes de saúde do trabalhador no SUS: a estratégia da RENAST. Ciência \& Saúde Coletiva, Rio de Janeiro, v. 10, n. 4, p. 817-828, 2005. http://dx.doi.org/10.1590/ S1413-81232005000400007

FERRIGNO, I. S. V. Terapia da mão: fundamentos para a prática clínica. São Paulo:Editora Santos, 2007.

FIGUEIREDO, I. M. et al. Ganhos Funcionais e sua relação com os componentes de função em trabalhadores com lesão de mão. Revista Brasileira de Fisioterapia, São Carlos, v. 10, n. 4, p. 421-427, 2006. http://dx.doi. org/10.1590/S1413-35552006000400010
LACAZ, F. A. C. O campo saúde do trabalhador: resgatando conhecimentos e práticas sobre as relaçóes trabalho-saúde. Cadernos de Saúde Pública, Rio de Janeiro, v. 23, n. 4, p. 757-766, 2007. http://dx.doi.org/10.1590/ S0102-311X2007000400003

LEBRÃO, M. L.; JORGE, M. H. P. M.; LAURENTI, R. Morbidade hospitalar por lesóes e envenenamentos. Revista de Saúde Pública, São Paulo, v. 31, n. 4, p. 26-37, 1997. http://dx.doi.org/10.1590/S0034-89101997000500003

LEITE, T. A. A. F. As mãos na interação do indivíduo consigo e com o mundo: uma reflexão em prol da reabilitação "física”. O Mundo da Saúde, São Paulo, v. 30, n. 1, p. 129-140, 2006.

MACHADO, J. M. H.; GOMEZ, C. M. Acidentes de trabalho: uma expressão da violência social. Cadernos de Saúde Pública, Rio de Janeiro, v. 10, n. 1, p. 74-87,1994.

MATTAR JUNIOR, R. Lesões traumáticas da mão. Revista Brasileira de Ortopedia, Rio de Janeiro, v. 36, n. 10, p. 359-366, 2001.

PARDINI JUNIOR, A. G. et al. Lesões da mão em acidentes de trabalho: análise de 1.000 casos. Revista Brasileira de Ortopedia, Rio de Janeiro, v. 25, n. 5, p. 119-124, 1990.

SANTANA, V. S. et al. Acidentes de trabalho: custos previdenciários e dias de trabalho perdidos. Revista de Saúde Pública, São Paulo, v. 40, n. 6, p. 1004-1012, 2006. http://dx.doi.org/10.1590/S0034-89102006000700007 SILVA, S. R.; GUIMARÃES, E. V.; RODRIGUES, A. M. V. N. Aspectos relacionados ao processo de retorno ao trabalho de indivíduos com desordens musculoesqueléticas do membro superior: uma bibliografia comentada. Revista de Terapia Ocupacional da USP, Sáo Paulo, v. 18, n. 1, p. 38-43, 2007.

\section{Contribuição dos Autores}

Tamara Pereira de Oliveira: Responsável pela concepção e redação do texto manuscrito. Mariana Midori Sime: Responsável pela organização das fontes, análise e revisão do texto final. Jucimara Firmo Barreto Costa: Responsável pela orientaçáo à pós-graduanda e pela redação e revisão do texto. Iracema Serrat Vergotti Ferrigno: Responsável pela orientação à pós-graduanda, redação e revisão do texto.

\section{Notas}

${ }^{1}$ Trata-se de pesquisa realizada como Trabalho de Conclusão de Curso do curso de pós-graduação lato-sensu de Terapia da Mão e Reabilitação do Membro Superior, realizado na Universidade Federal de São Carlos no período de abril de 2009 a agosto de 2010 . 


\section{Anexo}

Anexo 1. Quadro de causas de acidentes de trabalho conforme CID-10.

\section{Código de causa de acidentes CID-10}

V28 - motociclista traumatizado sem colisão (p. ex. capotamento).

V29.9 - acidente de moto não especificado.

V49.6 - acidente de carro não especificado.

V79 - acidente de ônibus não especificado.

V79.3 - acidente de ônibus, não de trânsito.

V87.9 - pessoa traumatizada em outros acidentes de trânsito, veículo não motorizado.

V99 - acidente de transporte.

W01 - queda no mesmo nível por escorregão, tropeção.

W09 - queda de equipamento de playground.

W11 - queda de escada de mão.

W13 - queda para fora do edifício (p. ex. da janela, muro).

W18 - outras quedas do mesmo nível (p. ex. choque).

W20 - impacto por objeto lançado, projetado ou em queda.

W22 - impacto acidental ativo ou passivo causado por outros objetos (p. ex. choque contra um muro).

W23 - esmagado, comprimido entre objetos.

W24 - contato com elevadores e instrumentos de transmissão, não classificado (p. ex. polia, cabo de trasmissão).

W26 - contato com faca.

W27 - ferramenta manual sem motor.

W28 - contato com segadeira motorizada para cortar grama.

W29 - contato com outros utensílios manuais e aparelhos domésticos equipados com motor (p. ex. serra circular, ventilador).

W31 - contato com máquina.

W40 - explosão de outros materiais (p. ex. artesanal ou de fábrica).

W49 - exposição a forças mecânicas não especificadas.

X10 - contato com fonte de calor ou substância quente.

X30 - exposição a calor natural excessivo.

X58 - exposição a outros fatores especificados.

X99 - agressão por meio de objetos cortantes ou penetrantes.

Y35.3 - intervenção legal envolvendo o uso de objetos contundentes (p. ex. golpe por cassetete).

Y35.4 - intervenção legal envolvendo o uso de objetos cortantes ou penetrantes. 
Anexo 2. Quadro de diagnóstico da lesão conforme CID-10.

\section{Diagnóstico da lesão CID-10}

S46 - traumatismo de tendão e músculo.

S60.0 - contusão de dedo sem lesão de unha.

S60.2 - contusão de outras partes do punho.

S61 - ferimento do punho.

S61.0 - ferimento de dedo sem lesão de unha.

S61.1 - ferimento de dedo com lesão de unha.

S62 - fratura em nível de punho e extremidade distal de rádio.

S62.0 - fratura de escafóide.

S62.4 - fratura múltipla dos metacarpos.

S62.5 - fratura de polegar.

S62.6 - fratura de outros dedos.

S62.8 - fratura de outras partes do punho e da mão.

S63.1 - luxação de dedo.

S63.6 - entorse e distensão de dedos.

S66 - traumatismo de músculo e tendão ao nível do punho.

S67.0 - lesão por esmagamento do polegar e de outros dedos.

S68 - amputaçáo traumática em nível de punho e mão.

S68.1 - amputação traumática de um dedo.

S68.2 - amputação de dois ou mais dedos.

S68.3 - amputaçáo traumática combinada de partes de dedo associada a outras partes de punho.

S69.9 - traumatismo não especificado do punho.

T01.9 - ferimentos múltiplos não especificados.

T05.9 - amputaçôes múltiplas não especificadas.

T07 - traumatismo múltiplo não especificado. 